\title{
Strategi Pengembangan Kompetensi Sumber Daya Manusia Pasca Unloading dari Kapal Ternak Camara Nusantara Indonesia
}

\author{
Strategy Development of Human Resources Competency Post Unloading from Indonesian Camara Nusantara \\ Cattle Ship \\ G. M. Toharmat ${ }^{1 *}$, A. M. Fuah ${ }^{1}$, L. Cyrilla ${ }^{1}$, \& Y. Triyonggo ${ }^{2}$ \\ ${ }^{1}$ Department of Animal Production and Technology, Faculty of Animal Science, IPB University, Agatis St, \\ Campus IPB Darmaga, Bogor 16680, Indonesia \\ ${ }^{2}$ Director of Human Resources of Bridgestone Tire Indonesia Ltd, Bekasi, 17124 \\ *Corresponding author: mutdaman@gmail.com \\ (Received 19-12-2019; Revised 01-01-2020; Accepted 17-01-2020)
}

\begin{abstract}
The purpose of this study was to create strategy for developing Human Resource competency post unloading from Camara Nusantara Cattle Ship. Analytic Hierarchy Process (AHP) method were used for search the best alternative strategy for developing Human Resource competency post unloading from Camara Nusantara Cattle Ship. The expert selection was carried out to obtain priority weights or rankings in the AHP structure to determine post-unloading HR competency development strategies. Based on the results of the analysis that has been done that the most influential factor is facilities and infrastructure with a weight of 0.377 . The actor who has the most role in determining the strategy to increase the competence of human resources after unloading from cattle ship is an expedition company with a weight of 0.269 , with the primary objective being to maintain the quality of livestock (0.464). The most appropriate alternative strategy in the hierarchy with a weight of 0.324 is conducting competencybased training and development.
\end{abstract}

Keywords: competency development strategy, AHP, livestock transport, animal welfare.

\begin{abstract}
ABSTRAK
Tujuan dari penelitian ini adalah untuk merumuskan strategi untuk mengembangkan kompetensi sumber daya manusia (SDM) pasca pembongkaran dari Kapal Ternak Camara Nusantara. Metode Analytic Hierarchy Process (AHP) digunakan untuk mencari strategi terbaik untuk mengembangkan kompetensi SDM pasca-pembongkaran dari Kapal Ternak Camara Nusantara. Penilaian oleh pakar dilakukan untuk mendapatkan bobot prioritas atau peringkat dalam struktur AHP untuk menentukan strategi pengembangan kompetensi SDM pasca pembongkaran. Berdasarkan hasil analisis yang telah dilakukan bahwa faktor yang paling berpengaruh adalah sarana dan prasarana dengan bobot 0.377 . Aktor yang paling berperan dalam menentukan strategi untuk meningkatkan kompetensi SDM pasca pembongkaran dari kapal ternak adalah perusahaan ekspedisi dengan bobot 0.269; dengan tujuan utama menjaga kualitas ternak (0.464). Strategi alternatif yang paling tepat dalam hierarki dengan bobot 0.324 adalah melakukan pelatihan dan pengembangan berbasis kompetensi.
\end{abstract}

Kata kunci : strategi pengembangan kompetensi, AHP, transportasi ternak, kesejahteraan hewan.

\section{PENDAHULUAN}

Perilaku konsumen Indonesia yang lebih menyukai daging segar dibandingkan daging beku mendorong produsen untuk mengirim sapi hidup dari daerah produksi yang kebanyakan berada di luar pulau Jawa ke daerah konsumen. Indonesia belum memiliki regulasi, pedoman, dan standar-standar yang mengatur penanganan ternak ketika dilakukan transportasi. Transportasi ternak merupakan hal berisiko bagi hewan ternak dan industri. Risiko yang dapat terjadi adalah susut berat badan ternak, kematian, dan luka pada ternak. Transportasi ternak yang baik harus memperhatikan kesejahteraan hewan. Broom (2007) menyatakan penanganan, pemuatan, pengangkutan dan pembongkaran hewan dapat memiliki efek yang sangat besar pada kesejahteraan hewan. Pelaksanaan proses transportasi ternak juga perlu memperhatikan penyediaan sarana dan fasilitas yang baik serta Sumber Daya Manusia 
(SDM) yang terlatih sehingga proses transportasi ternak berjalan dengan baik.

Sentra sapi potong berada di Indonesia timur, sedangkan konsumen terbesar berada di kota besar seperti Jakarta, Surabaya, dan Medan, hal tersebut mendorong pemerintah membuat konsep logistik Tol Laut yang salah satu programnya adalah kapal ternak. Kapal ternak yang diberi nama KM Camara Nusantara berkapasitas angkut 500 ekor sapi yang berfungsi mengirim sapi hidup dari sentra sapi potong ke sentra konsumen. Mekanisme transportasi ternak hidup dengan menggunakan Kapal Ternak Camara Nusantara lebih efektif dari pada sistem transportasi konvensional (Haryana dan Nuryati 2016). Menurut Dirjen Perhubungan Laut tujuan dari dibuatnya kapal ternak adalah untuk meningkatkan efektivitas kegiatan pengangkutan ternak antara lain mengurangi susut bobot saat transportasi dan mengurangi biaya transportasi, tujuan lainnya adalah untuk mendukung program ketahanan pangan.

Salah satu faktor yang dapat mendukung pencapaian tujuan dari dibuatnya Kapal Ternak ini adalah Sumber Daya Manusia (SDM) yang berkualitas. Selama proses pengiriman ternak dari Nusa Tenggara Timur (NTT) ke Jakarta menggunakan kapal ternak tidak hanya SDM di atas kapal saja yang akan mempengaruhi pencapaian tujuan dari dibangunnya kapal ternak ini. Harus diperhatikan juga SDM di luar kapal ternak yang mendukung proses pengiriman ternak, contohnya adalah pekerja bongkar muat dan sopir ternak.

Pemulihan ternak yang dikirim menggunakan kapal ternak dilakukan di kandang pembeli sapi. Penurunan atau pembongkaran ternak dari kapal menjadi berisiko dikarenakan ternak yang telah berlayar selama beberapa hari langsung digiring ke dalam truk untuk dikirim ke tempat tujuan. Saat melakukan pekerjaannya pekerja bongkar ternak dan sopir angkutan ternak melakukan interaksi dengan ternak. Hemsworth dan Coleman (2011) mengusulkan model yang menunjukkan sikap perawat ternak yang negatif terhadap ternak menyebabkan interaksi yang negatif dari ternak. Interaksi negatif tersebut dapat menyebabkan meningkatnya ketakutan ternak pada manusia, disertai stres kronis. Ketakutan terhadap manusia dan stres ini akan mempengaruhi kesejahteraan hewan dan produktivitasnya. Hubungan yang baik dengan ternak dapat dikaitkan dengan status kesehatan ternak yang lebih baik.

Perilaku pekerja bongkar dan sopir yang kasar atau negatif tidak hanya akan menyebabkan ternak menjadi stres tetapi juga akan mengurangi kualitas ternak yang ditransportasikan. Strategi untuk pengembangan kompetensi tenaga kerja pasca unloading dari kapal ternak diperlukan agar kompetensi tenaga kerja dapat meningkat sehingga ternak dapat terjaga kesehatannya dan terjamin kesejahteraannya agar risiko saat pengiriman ternak dapat berkurang. Kompetensi SDM yang baik akan berkontribusi dalam mengoptimalkan proses transportasi ternak dari kapal Ternak Camara ke kandang tujuan. Penelitian ini bertujuan untuk merumuskan strategi pengembangan kompetensi tenaga kerja pasca unloading dari Kapal Ternak Camara Nusantara Indonesia.

\section{METODE}

\section{Waktu dan Tempat Penelitian}

Penelitian dilaksanakan di pelabuhan kedatangan Kapal Ternak Camara Nusantara yaitu Pelabuhan Tanjung Priok Jakarta, perusahaan pengangkutan ternak, dan kandang yang menerima ternak dari Kapal Ternak Camara Nusantara. Penelitian ini dilaksanakan pada bulan Juli hingga bulan September tahun 2019.

\section{Prosedur Penelitian}

\section{Pengumpulan data}

Pengumpulan data primer yang dilakukan melalui pengamatan langsung saat proses unloading dari Kapal Ternak Camara Nusantara 3 di Pelabuhan Tanjung Priok dan wawancara kepada pekerja pasca unloading serta pakar yang telah dipilih berdasarkan kapabilitas dan pengalaman terkait peternakan atau transportasi ternak di Indonesia. Data sekunder diperoleh dari studi pustaka dan laporan dari institusi terkait.

\section{Analytic Hierarchy Process (AHP)}

Metode AHP merupakan pendekatan dasar dalam pengambilan keputusan. Metode AHP dapat menyelesaikan masalah multi kriteria yang kompleks menjadi sebuah hierarki (Saaty dan Vargas 2012). Prinsip kerja AHP yaitu penyederhanaan suatu persoalan kompleks yang tidak terstruktur, strategis, dan dinamik menjadi bagianbagiannya, serta menata dalam suatu hierarki. Kemudian tingkat kepentingan setiap variabel diberi nilai numerik secara subjektif tentang arti penting variabel tersebut secara relatif dibandingkan dengan variabel yang lain, kemudian dilakukan sintesa untuk menetapkan variabel yang memiliki prioritas tinggi dan berperan untuk mempengaruhi hasil pada sistem tersebut (Marimin dan Maghfiroh 2011).

Analisis AHP pada penelitian ini dilakukan menggunakan software Expert Choice 11. Menurut Saaty (2008), prinsip kerja AHP adalah sebagai berikut:

1. Penyusunan Hierarki. Persoalan yang akan diselesaikan, diuraikan menjadi unsur-unsurnya, yaitu faktor, aktor, tujuan, dan alternatif yang kemudian disusun menjadi struktur hierarki.

2. Penilaian Kriteria dan Alternatif. Kriteria dan alternatif dinilai melalui perbandingan berpasangan. Menurut Saaty dan Vargas (2012), untuk berbagai persoalan skala 1 sampai 9 adalah skala terbaik dalam mengekspresikan pendapat. Nilai dan definisi pendapat kualitatif dari skala perbandingan dapat dilihat pada Tabel 1 .

3. Penentuan Prioritas. Setiap Kriteria dan alternatif dilakukan perbandingan berpasangan (pairwise comparison). Nilai-nilai perbandingan relatif diolah untuk menentukan peringkat relatif dari seluruh alternatif. Baik kriteria kualitatif maupun kriteria kuantitatif dapat dibandingkan sesuai dengan pertimbangan yang telah ditentukan untuk menghasilkan bobot dan prioritas.

4. Konsistensi Logis. Semua elemen dikelompokkan secara logis dan diperingkatkan secara konsisten sesuai dengan suatu kriteria yang logis. 
Tabel 1. Skala perbandingan

\begin{tabular}{cl}
\hline Nilai & \multicolumn{1}{c}{ Definisi } \\
\hline 1 & Elemen A sama penting dengan alternatif B \\
3 & Elemen A sedikit lebih penting dari B, atau sebaliknya \\
5 & Elemen A jelas lebih penting dari B, atau sebaliknya \\
7 & Elemen A sangat jelas lebih penting dari B, atau \\
& sebaliknya \\
9 & Elemen A mutlak lebih penting dari B, atau sebaliknya \\
$2,4,6,8$ & Apabila ragu-ragu antara dua nilai yang berdekatan. \\
\hline
\end{tabular}

\section{Pemilihan pakar}

Pemilihan pakar dilakukan untuk memperoleh bobot atau rangking prioritas pada struktur AHP untuk menentukan strategi pengembangan kompetensi SDM pasca unloading. Pemilihan pakar dalam penelitian ini adalah yang memiliki kapabilitas dan berpengalaman, atau orang-orang yang terlibat secara langsung dan atau berpengaruh dalam mengambil kebijakan dalam transportasi ternak di Indonesia dan mempunyai pengalaman di bidang peternakan, dan transportasi ternak. Dalam menganalisis alternatif untuk strategi pengembangan kompetensi SDM pasca unloading dari Kapal Ternak dilakukan pengumpulan pendapat dari delapan pakar yang dapat dilihat pada Tabel 2 .

Tabel 2. Pakar AHP

\begin{tabular}{|c|c|}
\hline No & Bidang keahlian pakar \\
\hline 1 & Dosen teknologi ternak Fakultas Peternakan IPB \\
\hline 2 & $\begin{array}{l}\text { Kepala Bidang Agribisnis, Dinas Peternakan } \\
\text { Provinsi NTT }\end{array}$ \\
\hline 3 & $\begin{array}{l}\text { Sekretaris Himpunan Pengusaha Peternak Sapi Ker- } \\
\text { bau (HP2SK), NYY }\end{array}$ \\
\hline 4 & Bagian Kesrawan, Ditjen PKH Kementan RI \\
\hline 5 & Dokter Kapal Camara Nusantara 1, PT PELNI \\
\hline 6 & Pengusaha Ternak, Sapi Bagus \\
\hline 7 & Kepala R\&D, PD Dharma Jaya \\
\hline 8 & Kepala Divisi Perdagangan, PD Dharmajaya \\
\hline
\end{tabular}

\section{HASIL DAN PEMBAHASAN}

Analytic Hierarchy Process (AHP) digunakan dalam penelitian ini untuk merumuskan kriteria dan alternatif strategi untuk peningkatan kompetensi SDM pasca unloading dari Kapal Ternak Camara Nusantara. Hierarki yang disusun dalam penelitian ini terdiri atas lima tingkat. Tingkat pertama adalah peningkatan kompetensi Sumber Daya Manusia Pasca unloading dari Kapal Ternak Camara Nusantara. Tingkat kedua berisikan faktor yang berpengaruh dalam peningkatan kompetensi SDM pasca unloading dari Kapal Ternak. Tingkat ke tiga adalah aktor yang berpengaruh dalam meningkatkan kompetensi SDM. Tingkat ke empat adalah tujuan yang terdiri atas tiga tujuan yaitu peningkatan kompetensi, mempertahankan kualitas produk, dan peningkatan kinerja. Tingkat ke lima terdapat pilihan alternatif dalam menentukan strategi. AHP diolah menggunakan program software Expert Choice 11, Software digunakan untuk menganalisis hasil pendapat para pakar. Marimin dan Magfiroh (2011) menyatakan bahwa nilai Cosistency Ratio (CR) tidak lebih dari 10\% menunjukkan data konsisten dan penilaian pakar dapat diterima. Skema hierarki AHP untuk Strategi Peningkatan Kompetensi SDM pasca unloading dari Kapal Ternak Camara Nusantara dapat dilihat pada Gambar 1.

Berdasarkan struktur hierarki pada Gambar 1, faktor yang memiliki tingkat pengaruh terbesar dalam strategi pengembangan kompetensi SDM pasca unloading dari Kapal Ternak Camara Nusantara adalah sarana dan prasarana (0.377). Faktor yang memiliki pengaruh terendah adalah peraturan pemerintah. Tujuan dari analisis faktor adalah melihat pengaruh faktor terhadap peningkatan kompetensi SDM pasca unloading dari Kapal Ternak. Bobot dan prioritas dari faktor penyusun dapat dilihat pada Tabel 3. Faktor selanjutnya yang mempengaruhi adalah kompetensi individu dengan bobot (0.304), lingkungan kerja dengan bobot (0.174), dan yang terakhir adalah peraturan pemerintah dengan bobot $(0.146)$.

Tabel 3. Bobot dan prioritas faktor terhadap Strategi Peningkat an kompetensi SDM Pasca unloading dari Kapal Ternak Camara Nusantara

\begin{tabular}{lcc}
\hline \multicolumn{1}{c}{ Unsur Faktor } & Bobot & Prioritas \\
\hline Sarana dan Prasarana & 0.377 & 1 \\
Kompetensi Individu & 0.304 & 2 \\
Lingkungan Kerja & 0.174 & 3 \\
Peraturan Pemerintah & 0.146 & 4 \\
\hline
\end{tabular}

Proses unloading ternak dilakukan di pelabuhan Tanjung Priok, Kapal Ternak Camara Nusantara merupakan Kapal Ternak yang memiliki kapasitas angkut 500 ekor sapi dibandingkan dengan Kapal Ternak Australia (MV Ocean Ute) yang dapat mengangkut 4000 ekor sapi. Desain Kapal Ternak Camara Nusantara mengikuti desain Kapal Ternak Australia tanpa memperhatikan perbedaan tingkah laku sapi lokal dan sapi yang diangkut dari Australia. Berdasarkan pengamatan dan wawancara dilapang terdapat perbedaan waktu yang dibutuhkan untuk proses unloading dari kapal ke truk.

Kapal Ternak Camara Nusantara Indonesia membutuhkan waktu sekitar 30 menit untuk menurunkan sapi dari kapal ke satu truk sedangkan waktu penurunan dari kapal impor Australia membutuhkan sekitar kurang dari 5 menit untuk mengisi satu truk. Penyebab dari waktu unloading yang lama pada Kapal Ternak Camara Nusantara Indonesia adalah ketika proses unloading sapi diikat dan ditarik satu persatu dengan tali oleh pekerja, dibandingkan sapi dari Australia yang berkoloni dan tidak perlu ditarik satu persatu menggunakan tali. Semakin lama durasi loading dan unloading tingkat stres yang dialami ternak semakin tinggi, penting bahwa loading dan unloading harus dilaksanakan tanpa ada penundaan dan dengan kesulitan minimal. Buruknya proses loading dan unloading ternak dapat diakibatkan oleh fasilitas yang tidak memadai atau pekerja yang tidak memenuhi persyaratan (Maria et al. 


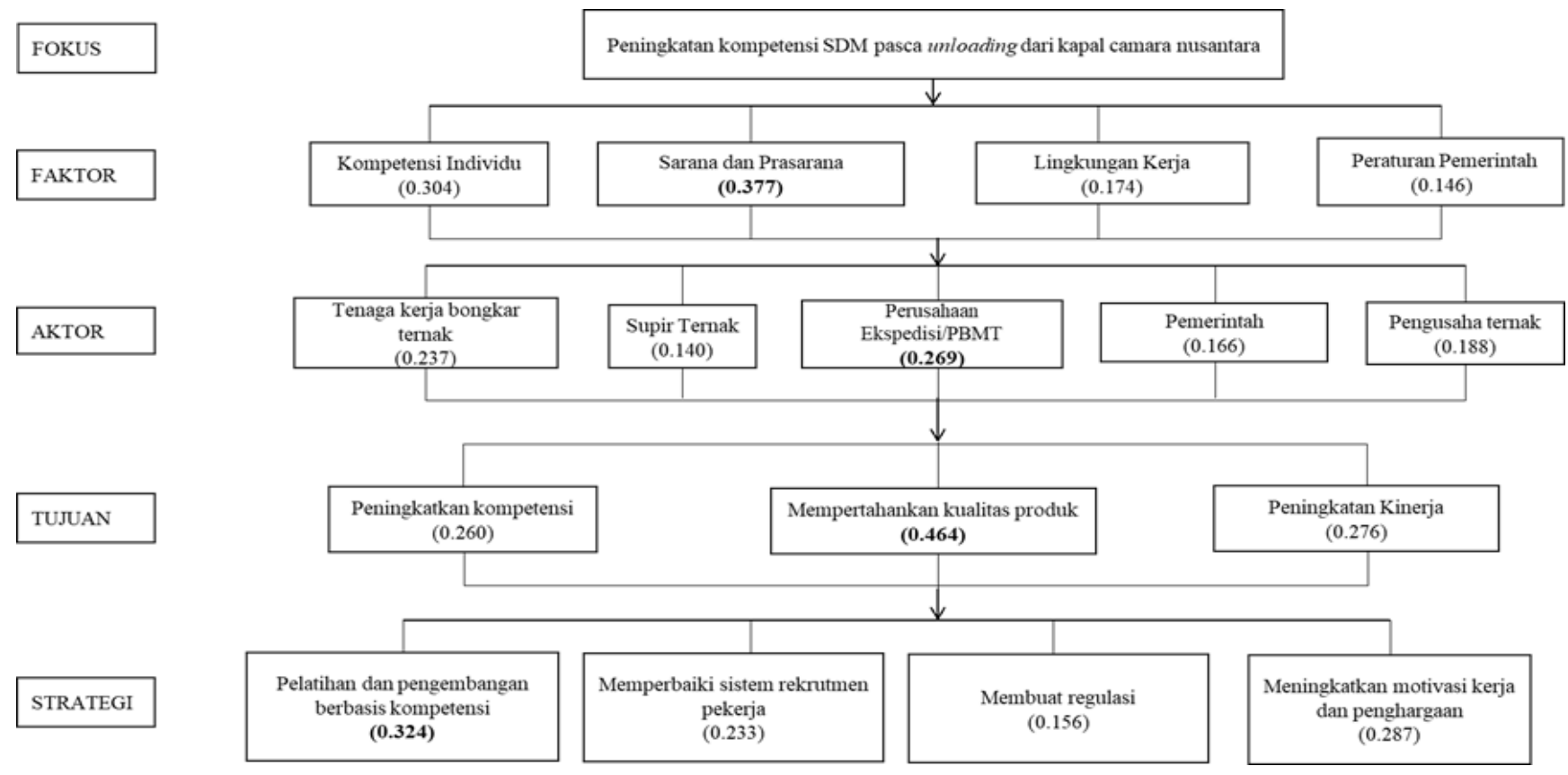

Gambar 1. Analytic Hierarchy Process (AHP)

2004). Jenis sapi yang dibawa oleh Kapal Ternak Camara adalah sapi Bali dan sapi Ongole (Sumba Ongole dan Rote Ongole). Perbedaan genetik dapat menjadi alasan beberapa ternak lebih mampu menahan berbagai dampak lingkungan terkait dengan penanganan dan transportasi serta kondisi kendaraan dan fasilitas bongkar muat sangat penting karena dapat mempengaruhi tingkat stres pada ternak (Broom 2007).

Elemen aktor pada Tabel 4 yang mempengaruhi strategi peningkatan kompetensi SDM pasca unloading Kapal Ternak Camara Nusantara. Perusahaan ekspedisi merupakan aktor yang paling berpengaruh dalam strategi pengembangan kompetensi SDM dengan bobot (0.269). Hal ini disebabkan karena perusahaan ekspedisi memiliki tanggung jawab penuh terhadap ternak yang di bongkar dari kapal dan ternak yang kemudian ditransportasikan ke tempat pembeli. Aktor selanjutnya yang mempengaruhi adalah tenaga kerja bongkar ternak dengan bobot (0.237), kemudian pengusaha ternak dengan bobot (0.188), pemerintah (0.166), dan sopir Ternak (0.140). Perusahaan ekspedisi memiliki tanggung jawab terhadap ternak dari mulai unloading dari Kapal Ternak hingga kandang tujuan.

Tabel 4. Bobot dan prioritas Aktor terhadap Strategi Peningkat an Kompetensi SDM Pasca unloading dari Kapal Ternak Camara Nusantara

\begin{tabular}{lcc}
\hline \multicolumn{1}{c}{ Unsur Aktor } & Bobot & Prioritas \\
\hline Perusahaan Ekspedisi/PBMT & 0.269 & 1 \\
Tenaga Kerja Bongkar Ternak & 0.237 & 2 \\
Pengusaha Ternak & 0.188 & 3 \\
Pemerintah & 0.166 & 4 \\
Sopir Ternak & 0.140 & 5 \\
\hline
\end{tabular}

Biaya bongkar dan transportasi ke kandang tujuan sebesar Rp 200.000,- tergantung dari jauhnya jarak yang dituju. Perusahaan ekspedisi bertanggung jawab langsung terhadap tenaga kerja bongkar ternak dan sopir. Biaya transportasi yang dibebankan oleh perusahaan sudah mencakup asuransi apabila terjadi sapi mati atau terluka selama perjalanan ke kandang.

Transportasi ternak hidup diketahui membuat stres dan dapat memiliki dampak langsung pada kesejahteraan hewan. Peningkatan kesejahteraan hewan dapat dicapai melalui penanganan ternak yang hati-hati dan praktik berkendara yang baik sebelum, selama, dan setelah transportasi. Tugas yang dilakukan oleh perusahaan pengangkut ternak sebagian besar melibatkan dasar-dasar penanganan ternak (stockmanship) dan ilmu peternakan. Peningkatan kualitas penanganan ternak selama transportasi dapat dilakukan dengan pemilihan personil dengan hatihati, berdasarkan kriteria spesifik dan ketat, atau diberikan pelatihan khusus untuk meningkatkan pengetahuan teknis dalam menangani ternak (Schwartzkopf-Genswein et al. 2008).

Pengangkutan ternak di Indonesia saat ini belum memiliki undang-undang atau peraturan yang mewajibkan pelatihan khusus dalam penanganan ternak. Menurut Animal Health Australia (AHA 2012), otoritas yang berkompeten bertanggung jawab untuk memastikan kesadaran dan pelatihan yang tepat dari yang menangani hewan, pengemudi, dan pengelola fasilitas dalam masalah yang relevan dalam kesejahteraan hewan. Individu yang terlibat dalam proses pengangkutan ternak dan prosedur penanganan yang terkait harus menerima pelatihan yang tepat dan kompeten untuk memenuhi tanggung jawab mereka.

Berdasarkan Tabel 5, prioritas utama unsur tujuan dengan bobot (0.464) adalah menjaga kualitas produk 
Tabel 5. Bobot dan prioritas tujuan terhadap Strategi Peningkat an Kompetensi SDM Pasca unloading dari Kapal Ternak Camara Nusantara

\begin{tabular}{lcc}
\hline \multicolumn{1}{c}{ Unsur Tujuan } & Bobot & Prioritas \\
\hline Menjaga Kualitas Produk (ternak) & 0.464 & 1 \\
Peningkatan Kinerja & 0.276 & 2 \\
Peningkatan Kompetensi & 0.260 & 3 \\
\hline
\end{tabular}

(ternak) agar kualitasnya terjaga dan mengurangi atau menghindari risiko-risiko selama proses unloading dan transportasi. Terjaganya kualitas ternak dari sejak diturunkan dari Kapal Camara hingga kandang pembeli ternak dapat menghindari kerugian yang dialami pengusaha ternak. Meskipun Indonesia belum memiliki peraturan dan standar terkait transportasi ternak, perusahaan ekspedisi sudah melakukan metode bongkar dan transportasi ternak berdasarkan peraturan yang dikeluarkan oleh eksportir dari Australia. Peningkatan kinerja menempati prioritas kedua dengan bobot (0.276), Prioritas terakhir adalah peningkatan kompetensi dengan bobot (0.260).

Perusahaan ekspedisi sebagai pelaksana transportasi ternak diharapkan dapat melaksanakan manajemen kualitas selama proses transportasi. Pelaksanaan manajemen kualitas dapat menjadi pilihan untuk meningkatkan kesejahteraan hewan dan mengurangi risiko kehilangan bobot badan ternak selama proses transportasi. Pelatihan terhadap personel atau pekerja untuk meningkatkan penanganan ternak dan aktivitas lainnya yang berhubungan dengan transportasi ternak harus menjadi kebutuhan dasar (Villa et all. 2008).

Kriteria alternatif pada Tabel 6 menunjukkan pelatihan dan pengembangan berbasis kompetensi menjadi prioritas utama dalam melakukan alternatif untuk strategi peningkatan kompetensi SDM pasca unloading dari Kapal Ternak Camara Nusantara dengan bobot nilai sebesar (0.324) lebih besar dibandingkan dengan meningkatkan motivasi kerja dan penghargaan (0.287), memperbaiki sistem rekrutmen pekerja dengan bobot (0.233) serta alternatif yang memiliki bobot terkecil adalah membuat regulasi dengan bobot $(0.130)$.

Tabel 6. Bobot dan prioritas alternatif terhadap Strategi Peningkatan kompetensi SDM Pasca unloading dari Kapal Ternak Camara Nusantara

\begin{tabular}{lcc}
\hline \multicolumn{1}{c}{ Unsur Alternatif } & Bobot & Prioritas \\
\hline $\begin{array}{l}\text { Pelatihan dan pengembangan ber- } \\
\text { basis kompetensi }\end{array}$ & 0.324 & 1 \\
$\begin{array}{l}\text { Meningkatkan motivasi kerja dan } \\
\text { penghargaan }\end{array}$ & 0.287 & 2 \\
$\begin{array}{l}\text { Memperbaiki sistem rekrutmen } \\
\text { pekerja }\end{array}$ & 0.233 & 3 \\
Membuat regulasi & 0.156 & 4 \\
\hline
\end{tabular}

Pelatihan dan pengembangan menjadi prioritas utama yang dapat berdampak langsung pada peningkatan kompetensi SDM pasca unloading dari Kapal Ternak Camara Nusantara. Pelatihan mengenai penanganan ternak selama transportasi, pengetahuan terkait kesejahteraan hewan dan perilaku ternak merupakan pengetahuan yang dapat diberikan untuk meningkatkan kompetensi SDM pasca unloading. Pelatihan dan pendidikan dapat menjadi cara termurah dan paling efektif untuk meningkatkan kesejahteraan hewan selama proses transportasi (Maria et all. 2004). Peningkatan kesejahteraan hewan dapat direalisasikan dengan mengetahui keterbatasan pekerja yang menangani ternak, pengawasan pekerja, dan memberikan pelatihan khusus dalam aspek kunci menangani ternak (Coleman dan Hemsworth 2014).

Berdasarkan hasil analisis, faktor yang paling berpengaruh adalah sarana dan prasarana dengan bobot 0.377. Aktor yang paling berperan dalam penentuan strategi untuk peningkatan kompetensi SDM pasca unloading dari kapal ternak adalah perusahaan ekspedisi dengan bobot 0.269 , dengan tujuan utamanya adalah menjaga kualitas ternak (0.464). Alternatif yang paling sesuai sebagai strategi untuk meningkatkan kompetensi SDM pasca unloading dari Kapal Ternak Camara Nusantara dengan bobot 0.324 adalah melakukan pelatihan dan pengembangan berbasis kompetensi.

\section{KESIMPULAN}

Alternatif strategi yang menjadi prioritas dalam peningkatan kompetensi SDM pasca unloading dari Kapal Ternak Camara Nusantara adalah pelatihan dan pengembangan pekerja berbasis kompetensi yang dapat dilaksanakan melalui pelatihan handling ternak, pelatihan dasar kesehatan ternak, dan pelatihan penerapan kesejahteraan hewan. Peningkatan motivasi kerja dengan pemberian penghargaan kerja, perbaikan sistem rekruitmen pekerja pasca unloading dan penetapan regulasi terkait penanganan ternak selama proses transportasi merupakan prioritas selanjutnya yang perlu disiapkan dan diterapkan oleh Instansi terkait. Aktor yang paling berperan adalah perusahaan ekspedisi ternak yang bertanggung jawab terhadap proses pengembangan kompetensi SDM pasca unloading dari kapal ternak sehingga kualitas ternak pada level konsumen tetap terjaga.

\section{KONFLIK KEPENTINGAN}

Kami menyatakan bahwa tidak ada konflik kepentingan dengan keuangan, pribadi, atau hubungan lain dengan orang atau organisasi lain yang terkait dengan materi yang dibahas dalam naskah.

\section{UCAPAN TERIMAKASIH}

Penulis mengucapkan terimakah kepada ALIN (animal logistics Indonesia Netherland) -NICHE (Netherland Initiative for Capacity Development in Higher Education) 2018-2019 untuk dukungan dana penelitian ini (NICHE/IDN.223). 


\section{DAFTAR PUSTAKA}

[AHA] Animal Health Australia. 2012. Australian Animal Welfare Standards and Guidelines-Land Transport of Livestock. Australian Government, Department of Agriculture, Fisheries and Forestry. Canberra. pp.7177.

Broom D M. 2007. Causes of poor welfare and welfare assessment during handling and transport. Livestock Handling and Transport. 3: 30-43.

Coleman G J, Hemsworth P H. 2014. Training To Improve Stockperson Beliefs and Behaviour Towards Livestock Enhances Welfare And Productivity. Rev. Sci. Tech, 33, pp.131-137.

[DAFF] Department of Agriculture, Fisheries and Forestry. 2011. Australian Standards for the Export of Livestock and Australian Position Statement on the Export of Livestock. Canberra (AUS): The Australian Government Department of Agriculture, Fisheries and Forestry.

Haryana A, Nuryati Y. 2016. Peran kapal ternak dalam memperlancar distribusi dan menekan biaya logistik daging sapi dari sentra produsen ke sentra konsumen di Indonesia. Jurnal Pusdiklat Perdagangan. 2(1): 78-85.

Hermsworth PH, Coleman GJ. 2011. Human-Livestock Interaction Second Edition: The stockperson and the Productvity and Welfare of Intersvely Farmed Animals. Chippenham (UK): CAB Internasional.
Ma'arif M S, Tanjung H. 2003. Teknik-Teknik Kuantitatif untuk Manajemen. Jakarta (ID): Gramedia Widiasarana Indonesia.

María G A, Villaroel M, Chacón G, Gebresenbet G. 2004. Scoring system for evaluating the stress to cattle of commercial loading and unloading. The Veterinary Record 154: 818 - 820

Marimin, Maghfiroh N. 2011. Aplikasi Pengambilan Keputusan dalam Rantai Pasok. Bogor (ID): IPB Press.

Saaty T L. 2008. Decision making with the analytic hierarchy process. Int. J Services Sciences. 1(1): 83-98.

Saaty T L, Vargas L G. 2012 The seven pillars of the analytic hierarchy process, Models, Methods, Concepts \& Applications of the Analytic Hierarchy Process. International Series in Operations Research \& Management Science. 175: 23-40.

Schwartzkopf-Genswein K S, Haley D B, Church S, Woods J, and O'Byrne T. 2008. An education and training programme for livestock transporters in Canada. Veterinaria Italiana. 44:273-283.

Villa P, Iannetti L, Di Francesco C, Di Pasquale A, Fiore G, Caporale V. 2008. Quality management for the road transportation of livestock. Veterinaria Italiana. 44. 187-200. 